\title{
The Student Well-Being Process Questionnaire (Student WPQ)
}

\author{
Gary M. Williams, Hannah Pendlebury, Kai Thomas, Andrew P. Smith* \\ Centre for Occupational and Health Psychology, School of Psychology, Cardiff University, Cardiff, UK \\ Email: *smithap@cardiff.ac.uk
}

How to cite this paper: Williams, G. M., Pendlebury, H., Thomas, K., \& Smith, A. P. (2017). The Student Well-Being Process Questionnaire (Student WPQ). Psychology, $8,1748-1761$.

https://doi.org/10.4236/psych.2017.811115

Received: August 2, 2017

Accepted: September 5, 2017

Published: September 8, 2017

Copyright $\odot 2017$ by authors and Scientific Research Publishing Inc. This work is licensed under the Creative Commons Attribution International License (CC BY 4.0).

http://creativecommons.org/licenses/by/4.0/

\begin{abstract}
Recent research has used short questionnaires based on single item versions of psychosocial concepts to assess well-being. This has largely been confined to occupational samples and the present article describes the extension of this process to university students. The Student Well-being Process Questionnaire (Student WPQ) was used to examine predictors of positive well-being, negative mental health and cognitive function. An online survey was used with 478 first and second year undergraduates as participants. Regression analyses showed that positive well-being (e.g. happiness, positive affect and life satisfaction) was predicted by positive personality (high optimism, self-esteem and self-efficacy), high social support and low stressors and low negative coping scores. Negative outcomes (e.g. perceived stress, anxiety and depression) were predicted by high stressor, coping and conscientiousness scores, and low positive personality and social support scores. Cognitive problems were predicted by high stressor and negative coping scores and low positive personality scores. A MANOVA showed that there were no significant interactions between the predictor variables. The best predictor of all outcomes was a combined score including all predictor variables. Overall, the present study shows that the Student WPQ can provide useful information on predictors of different aspects of well-being. Future research can include additional potential predictors and other outcomes to determine whether other factors are significant when established predictors are adjusted for.
\end{abstract}

\section{Keywords}

Well-Being; Student WPQ, Stressors, Personality, Social Support, Coping, Happiness, Life Satisfaction, Positive and Negative Affect, Perceived Stress, Anxiety and Depression

\section{Introduction}

Recent research has investigated well-being at work using an approach which 
includes occupational predictors (e.g. demands and resources) and individual effects (e.g. personality). These studies have been based on the Demands-Resources-Individual Effects model (DRIVE Model: Mark \& Smith, 2008). This model is flexible in that it allows for inclusion of new predictors and outcomes. Initial studies (e.g. Mark \& Smith, 2011, 2012) focused on predictors of anxiety and depression. Later studies (e.g. Williams \& Smith, 2016; Smith \& Smith, 2017; Williams, Pendlebury \& Smith, 2017; Williams, Thomas \& Smith, 2017) have also investigated predictors of positive well-being (happiness, positive affect and job satisfaction). As the number of predictors and outcomes grow so does the potential length of the questionnaire. In order to keep surveys as short as possible, our research has developed single item questions which have been shown to lead to the same predictive validity as multi-item scales. The original scale (the Well-being Process Questionnaire, WPQ) has been used with different occupational groups (e.g. nurses and university staff). It has led to the development of another questionnaire (the Smith Well-being Questionnaire-SWELL: Smith \& Smith, 2017a, b; Fan \& Smith, 2017a, b) which measures a wider range of predictors (e.g. addition of questions on the working environment and hours of work) and outcomes (e.g. absenteeism; presenteeism; sick leave; performance efficiency; work-life balance and illness caused or made worse by work). Alongside workplace well-being, the well-being of university students has also been studied for many years (Jones \& Johnston, 1997) and high levels of depression, anxiety, and stress have been reported in undergraduate students (Bayram \& Bilgel, 2008; Dahlin, Joneborg, \& Runeson, 2005). Many of the same concepts in the WPQ, including demands, resources, coping style, and personality have also been applied in this research.

Student related circumstances are frequently referred to in student well-being research, including fear of failing and long hours of study (Jones \& Johnston, 1997), social demands (Bayram \& Bilgel, 2008; Dahlin, et al., 2005; Tully, 2004) and lack of social support (Swickert, Rosentreter, Hittner, \& Mushrush, 2002). As a result, questionnaires have been specifically developed for assessing student specific circumstances that can impact well-being, such as the Inventory of College Students' Recent Life Experiences (ICSRLE) which includes factors such as time pressures, challenges to development, and social mistreatment (Kohn, Lafreniere, \& Gurevich, 1990). Research using the ISCRLE has also concluded that the variables involved should be acknowledged in the management of stress by businesses whose employees may also be students (Fogaratnam, 2004), further supporting the necessity of establishing the generalisability of the approach to other areas. Research on students' well-being has also acknowledged the impact of individual differences such as coping style and personality in the well-being process. Tully (2004) showed that non-direct coping strategies, including hostility and wishful thinking, were associated with higher levels of distress, as measured by the General Health Questionnaire (GHQ). Macan et al. (Macan, Shahani, Dipboye, \& Phillips, 1990) showed that those participating in greater time management behaviours (i.e. problem-focused coping) demonstrated greater job 
and life satisfaction and less tension. Kohn, Hay, \& Legere (1994) also reported that students who used emotion-focused coping reported higher perceived stress than those who scored low on this coping style. In terms of personality, Swickert et al. (2002) showed a significant main effect of extraversion on stress in undergraduate students and also provided evidence for the unique prediction of stress by extraversion and social support. Also of relevance to the research presented previously in the thesis is that in this study direct effects but not interactive effects were established, despite a correlation between the two predictor variables.

The present study was designed to confirm the multi-faceted approach to well-being in students using student-related demands based on single-item versions of the ICSRLE factors, resources based on single-item versions of the ISEL social support factors, and the previously used coping, personality, and outcome measures. The study also included a new set of items, cognitive problems, providing information on errors of memory, attention and action as well as productivity. If such measures are related to the WPQ predictors, then future research can assess academic attainment as well as well-being. Another feature of the present research was the application of the combined effects approach (Smith \& Mackay, 2001; Smith et al., 2004; Smith \& McNamara, 2015; Smith \& Wadsworth, 2015; Wellens \& Smith, 2006). Most of the previous research with the DRIVE model has shown that the predictors are independent and do not interact. This has led to consideration of their additive effects and the development of a combined effect score.

\section{Method}

\subsection{Participants}

The participants were 478 first and second year undergraduate Psychology students at Cardiff University (92.5\% female; age: $18-42$, 98\% $18-22$ years). The study was approved by the Ethics Committee, School of Psychology, Cardiff University, and carried out with the informed consent of the participants. At the end of the survey the participants were shown a debrief statement and awarded course credits for their participation.

\subsection{The Survey}

The survey was presented online using the Survey Tracker software.

\subsection{Questions}

The full set of questions is shown in Appendix 1. The majority were taken from the version of the WPQ used with workers. The additional questions are shown in Table 1 and measured student stressors, aspects of perceived social support and cognitive problems. The stressor items were developed to relate to students demands and resources and consisted of single-item measures of the 7 ICSRLE factors (Bodenhorn, Miyazaki, Ng, \& Zalaquett, 2007) and the 3 ISEL factors (Cohen, Mermelstein, Kamarck, \& Hoberman, 1985) (self-esteem was not 
Table 1. New items specific to student WPQ.

\begin{tabular}{|c|c|}
\hline $\begin{array}{l}\text { Questionnaire } \\
\text { sections }\end{array}$ & Single item measures \\
\hline $\begin{array}{l}\text { ICSRLE short } \\
\text { version: }\end{array}$ & $\begin{array}{l}\text { Please consider the following elements of student life and indicate to what } \\
\text { extent they have been a part of your life over past } 6 \text { months) } \\
\text { 1) Challenges to your development (e.g. important decisions about your } \\
\text { education and future career, dissatisfaction with your written or mathematical } \\
\text { ability, struggling to meet your own or others' academic standards). } \\
\text { 2) Time pressures (e.g. too many things to do at once, interruptions of your } \\
\text { school work, a lot of responsibilities). } \\
\text { 3) Academic Dissatisfaction (e.g. disliking your studies, finding courses } \\
\text { uninteresting, dissatisfaction with school). } \\
\text { 4) Romantic Problems (e.g. decisions about intimate relationships, conflicts } \\
\text { with boyfriends'/girlfriends' family, conflicts with boyfriend/girlfriend). } \\
\text { 5) Societal Annoyances (e.g. getting ripped off or cheated in the purchase of } \\
\text { services, social conflicts over smoking, disliking fellow students). } \\
\text { 6) Social Mistreatment (e.g. social rejection, loneliness, being taken advantage } \\
\text { of). } \\
\text { 7) Friendship problems (e.g. conflicts with friends, being let down or } \\
\text { disappointed by friends, having your trust betrayed by friends). }\end{array}$ \\
\hline $\begin{array}{l}\text { Social Support } \\
\text { (ISEL) short } \\
\text { version: }\end{array}$ & $\begin{array}{l}\text { Please state how much you agree or disagree with the following statements: } \\
\text { Tangible Support: There is a person or people in my life who would provide } \\
\text { tangible support for me when I need it (for example: money for tuition or } \\
\text { books, use of their car, furniture for a new apartment). } \\
\text { Belonging Support: There is a person or people in my life who would provide } \\
\text { me with a sense of belonging (for example: I could find someone to go to a } \\
\text { movie with me, I often get invited to do things with other people, I regularly } \\
\text { hang out with friends). } \\
\text { Emotional Support: There is a person or people in my life with whom I would } \\
\text { feel perfectly comfortable discussing any problems I might have (for example: } \\
\text { difficulties with my social life, getting along with my parents, sexual } \\
\text { problems). }\end{array}$ \\
\hline $\begin{array}{l}\text { Cognitive } \\
\text { Problems }\end{array}$ & $\begin{array}{l}\text { In the last two weeks did you find that you have problems of memory (e.g. } \\
\text { forgetting where you put things), attention (e.g. failures of concentration), or } \\
\text { action (e.g. doing the wrong thing)? } \\
\text { 1) While studying b. When not studying } \\
\text { How frequently in the last two weeks did you find that you were not getting as } \\
\text { much work done as you would have liked? } \\
\text { 2) While studying b. When not studying }\end{array}$ \\
\hline
\end{tabular}

included from the ISEL factors as it was already represented). The cognitive problem items were based on those used by Smith et al. (2004).

\subsection{Questions}

Six predictor variables were derived:

- Stressors (sum of ICSRLE questions)

- Social support (sum of ISEL questions)

- Positive personality (optimism + self-esteem + self-efficacy

- Negative coping (Blame self + wishful thinking + avoidance)

- Positive coping (Problem solving + seeks social support)

- Conscientiousness (single question) 
Three outcome variables were derived:

- Positive outcomes (happiness + positive affect + life satisfaction + Warwick-Edinburgh short items)

- Negative outcomes (anxiety + depression + stress)

- Cognitive problems (sum of items)

\section{Results}

The predictor variables were entered into linear regressions with each of the outcomes as a dependent variable. The results of these analyses are shown in Table 2.

Table 2. Regressions showing significant predictors for the three outcomes. (a) Negative outcomes. (b) Positive outcomes. (c) Cognitive problems.

(a)

\begin{tabular}{|c|c|c|c|c|c|}
\hline \multirow[t]{2}{*}{ Model } & \multicolumn{2}{|c|}{$\begin{array}{c}\text { Unstandardized } \\
\text { Coefficients }\end{array}$} & \multirow{2}{*}{$\begin{array}{c}\text { Standardized } \\
\text { Coefficients }\end{array}$} & \multirow[t]{2}{*}{$\mathrm{t}$} & \multirow{2}{*}{ Sig. } \\
\hline & B & S.E. & & & \\
\hline Stressors & 0.142 & 0.026 & 0.184 & 5.412 & 0.000 \\
\hline Social support & -0.148 & 0.042 & -0.125 & -3.513 & 0.000 \\
\hline Negative coping & 0.315 & 0.046 & 0.225 & 6.900 & 0.000 \\
\hline Positive coping & 0.134 & 0.089 & 0.055 & 1.501 & 0.134 \\
\hline Positive personality & -0.567 & 0.043 & -0.539 & -13.206 & 0.000 \\
\hline Conscientiousness core & 0.314 & 0.112 & 0.087 & 2.795 & 0.005 \\
\hline
\end{tabular}

(b)

\begin{tabular}{ccccccc}
\hline \multirow{2}{*}{ Model } & \multicolumn{2}{c}{$\begin{array}{c}\text { Unstandardized } \\
\text { Coefficients }\end{array}$} & $\begin{array}{c}\text { Standardized } \\
\text { Coefficients }\end{array}$ & \multirow{2}{*}{$\mathrm{t}$} & \multirow{2}{*}{ Sig. } \\
\cline { 2 - 5 } & $\mathrm{B}$ & S.E. & Beta & & \\
\hline Stressors & -0.089 & 0.035 & -0.075 & -2.551 & 0.011 \\
Social support & 0.318 & 0.056 & 0.175 & 5.671 & 0.000 \\
Negative coping & -0.206 & 0.060 & -0.096 & -3.418 & 0.001 \\
Positive coping & 0.128 & 0.117 & 0.035 & 1.094 & 0.275 \\
Positive personality & 1.025 & 0.057 & 0.635 & 18.138 & 0.000 \\
Conscientiousness core & 0.226 & 0.148 & 0.041 & 1.528 & 0.127 \\
\hline
\end{tabular}

(c)

\begin{tabular}{|c|c|c|c|c|c|}
\hline \multirow[t]{2}{*}{ Model } & \multicolumn{2}{|c|}{$\begin{array}{l}\text { Unstandardized } \\
\text { Coefficients }\end{array}$} & \multirow{2}{*}{$\begin{array}{c}\text { Standardized } \\
\text { Coefficients } \\
\text { Beta }\end{array}$} & \multirow[t]{2}{*}{$\mathrm{t}$} & \multirow[t]{2}{*}{ Sig. } \\
\hline & B & S.E. & & & \\
\hline Stressors & 0.038 & 0.019 & 0.104 & 2.026 & 0.043 \\
\hline Social support & -0.009 & 0.030 & -0.016 & -0.304 & 0.761 \\
\hline Negative coping & 0.157 & 0.033 & 0.237 & 4.814 & 0.000 \\
\hline Positive coping & 0.032 & 0.063 & 0.028 & 0.507 & 0.612 \\
\hline Positive personality & -0.083 & 0.031 & -0.164 & -2.652 & 0.008 \\
\hline Conscientiousness core & -0.152 & 0.080 & -0.090 & -1.906 & 0.057 \\
\hline
\end{tabular}


Positive well-being was predicted by high positive personality, high social support and low stressor and low negative coping scores. Negative outcomes were predicted by high stressor, coping and conscientiousness scores, and low positive personality and low social support scores. Cognitive problems were predicted by high stressor and negative coping scores and low positive personality scores.

A MANOVA was carried out to examine interactions and none of the interaction terms were significant. The predictor variables were then categorised by quartile splits. These quartile scores were summed to produce the combined predictor score (high scores being more positive) which was then categorised as quartiles. A MANOVA revealed that the combined score had a significant effect on all outcomes, with scores changing in the predicted direction across the four quartiles (see Table 3).

\section{Discussion}

The present study aimed to extend the use of an adapted DRIVE model and the use of the WPQ to a student sample. A new measure of student specific demands was created (the short ICSRLE) and a new measure of social support (based on the ISEL) created. Other measures (coping and personality) were from the original WPQ. The results showed that these measures could predict both positive and negative outcomes. In addition, an additional measure, cognitive problems, was included and the same variables also predicted variation in this. There was no evidence of interactions between the variables and a combined effects score was calculated by summing the predictors. All three outcomes showed the predicted changes across the quartiles of the combined effects score. Overall, these results confirm that a short measuring instrument can demonstrate predicted variation in well-being measures. The addition of the cognitive problems scores

Table 3. Outcome scores (means, s.d.s) for each quartile of the combined effects score.

\begin{tabular}{|c|c|c|c|}
\hline & $\begin{array}{l}\text { Combined effects } \\
\text { (quartiles) } \\
(1=\text { most negative } \\
\text { to } 4=\text { most } \\
\text { positive) }\end{array}$ & Mean & Std. Deviation \\
\hline \multirow{4}{*}{$\begin{array}{c}\text { Positive outcomes } \\
\text { (high scores }=\text { more } \\
\text { positive) }\end{array}$} & 1 & 35.59 & 8.77 \\
\hline & 2 & 43.60 & 9.02 \\
\hline & 3 & 50.57 & 6.72 \\
\hline & 4 & 56.06 & 6.69 \\
\hline \multirow{4}{*}{$\begin{array}{c}\text { Negative outcomes } \\
\text { (high scores }=\text { more } \\
\text { negative) }\end{array}$} & 1 & 25.40 & 4.88 \\
\hline & 2 & 21.03 & 6.46 \\
\hline & 3 & 16.74 & 5.83 \\
\hline & 4 & 14.15 & 5.19 \\
\hline \multirow{4}{*}{$\begin{array}{l}\text { Cognitive problems } \\
\text { (high scores = more } \\
\text { cognitive problems) }\end{array}$} & 1 & 9.01 & 3.54 \\
\hline & 2 & 8.38 & 2.86 \\
\hline & 3 & 6.89 & 2.97 \\
\hline & 4 & 6.45 & 3.30 \\
\hline
\end{tabular}


suggests that it will be possible to examine other relevant outcomes such as academic attainment. Other predictor variables (e.g. health-related factors; life style variables) can now be examined using the same approach. The "core" variables studied here can, in these future studies, be included as covariates. This will allow one to determine whether a study is sensitive enough to demonstrate established effects and also to see whether any new effects are independent or related to the "core" variables. Alternative methods of analyses can also be used in future research. Recent studies of the WPQ have either used categories of variables as in the present study or have conducted factor analyses and used the factor scores in the regression (Williams, Pendlebury \& Smith, 2017; Williams, Thomas \& Smith, 2017). An alternative approach is to pay more attention to the individual variables (both predictors and outcomes-Williams \& Smith, 2016).

\section{Limitations}

Although the present approach has received a great deal of support in this study one must be aware that it could reflect the context. First, this was a cross-sectional study and further longitudinal research is needed to obtain a better indication of causality. The approach needs to be used in other cultures and with samples differing in other demographic characteristics. One could also suggest that an even smaller number of questions could be used with each reflecting the groups of predictors and outcomes used here. This last point has been examined and has led to the development of a short version of SWELL (Smith \& Smith, 2017).

\section{Conclusion}

In conclusion, the Student WPQ has been shown to provide clear predictors of both positive and negative outcomes. These predictors appear to be independent and additive, with a combined effects score showing expected variation across quartiles. The addition of questions relating to cognitive problems suggests that the present approach may also be applied to topics such as academic attainment. Indeed, this could lead to the inclusion of both objective (e.g. Grade Point Average scores) and subjective (e.g. perception of efficiency of working) outcomes. The interface between well-being and academic work can also become more focused by including outcomes relating to both academic life (e.g. academic stress) and life in general.

\section{References}

Bayram, N., \& Bilgel, N. (2008). The Prevalence and Socio-Demographic Correlations of Depression, Anxiety and Stress among a Group of University Students. Social Psychiatry and Psychiatric Epidemiology, 43, 667-672. https://doi.org/10.1007/s00127-008-0345-X

Bodenhorn, N., Miyazaki, Y., Ng, K.-M., \& Zalaquett, C. (2007). Analysis of the Inventory of College Students' Recent Life Experiences. Multicultural Learning and Teaching, 2, 65-77. https://doi.org/10.2202/2161-2412.1022

Cohen, S., Mermelstein, R., Kamarck, T., \& Hoberman, H. (1985). Measuring the Func- 
tional Components of Social Support. In I. G. Sarason \& B. Sarason (Eds.), Social support: Theory, Research, and Applications (pp. 73-94). The Hague: MartinusNijhoff. https://doi.org/10.1007/978-94-009-5115-0_5

Dahlin, M., Joneborg, N., \& Runeson, B. (2005). Stress and Depression among Medical Students: A Cross-Sectional Study. Medical Education, 39, 594-604. https://doi.org/10.1111/j.1365-2929.2005.02176.x

Fan, J., \& Smith, A. P. (2017). The Impact of Workload and Fatigue on Performance. In L. Longo, \& M. C. Leva (Eds.), Human Mental Workload: Models and Applications. H-WORKLOAD 2017. Communications in Computer and Information Science (Vol. 726, pp. 90-105). Cham.: Springer. https://doi.org/10.1007/978-3-319-61061-0_6

Fogaratnam, G. B. P. (2004). Balancing the Demands of School and Work: Stress and Employed Hospitality Students. International Journal of Contemporary Hospitality Management, 16, 237-245. https://doi.org/10.1108/09596110410537397

Jones, M. C., \& Johnston, D. W. (1997). Distress, Stress and Coping in First-Year Student Nurses. Journal of Advanced Nursing, 26, 475-482. https://doi.org/10.1046/j.1365-2648.1997.t01-5-00999.x

Kohn, P. M., Hay, B. D., \& Legere, J. J. (1994). Hassles, Coping Styles, and Negative Well Being. Personality and Individual Differences, 17, 169-179. https://doi.org/10.1016/0191-8869(94)90023-X

Kohn, P. M., Lafreniere, K., \& Gurevich, M. (1990). The Inventory of College Students' Recent Life Experiences: A Decontaminated Hassles Scale for a Special Population. Journal of Behavioral Medicine, 13, 619-630. https://doi.org/10.1007/BF00844738

Macan, T. H., Shahani, C., Dipboye, R. L., \& Phillips, A. P. (1990). College Students' Time Management: Correlations with Academic Performance and Stress. Journal of Educational Psychology, 82, 760-768. https://doi.org/10.1037/0022-0663.82.4.760

Mark, G. M., \& Smith, A. P. (2008). Stress Models: A Review and Suggested New Direction. In J. Houdmont, \& S. Leka (Eds.), Occupational Health Psychology: European Perspectives on Research, Education and Practice (Vol. 3, pp. 111-144). EA-OHP Series, Nottingham University Press.

Mark, G., \& Smith, A. P. (2011). Effects of Occupational Stress, Job Characteristics, Coping and Attributional Style on the Mental Health and Job Satisfaction of University Employees. Anxiety, Stress and Coping, 25, 63-78. https://doi.org/10.1080/10615806.2010.548088

Mark, G., \& Smith, A. P. (2012). Occupational Stress, Job Characteristics, Coping and Mental Health of Nurses. British Journal of Health Psychology, 17, 505-521. https://doi.org/10.1111/j.2044-8287.2011.02051.x

Smith, A., \& Mackay, C. (2001). Combined Effects of Occupational Health Hazards. In M. Hanson (Ed.), Contemporary Ergonomic 2001 (pp. 179-184). London: Taylor \& Francis.

Smith, A., McNamara, R., \& Wellens, B. (2004). Combined Effects of Occupational Health Hazards (Report 287). HSE Contract Research. HSE Books.

Smith, A. P., \& McNamara, R. L. (2015). The Combined Effects of Occupational Stressors on Health and Wellbeing in the Offshore Oil Industry. In S. Sharples, S. Shorrock, \& P. Waterson (Eds.), Contemporary Ergonomics and Human Factors 2015 (pp. 423-429). London: Taylor \& Francis.

Smith, A. P., \& Smith, H. N. (2017). An International Survey of the Wellbeing of Employees in the Business Process Outsourcing Industry. Psychology, 8, 160-167. https://doi.org/10.4236/psych.2017.81010 
Smith, A. P., \& Smith, H. N. (2017). Workload, Fatigue and Performance in the Rail Industry. In L. Longo, \& M. C. Leva (Eds.), H-WORKLOAD 2017: Human Mental Workload: Models and Applications (pp. 251-263). Communications in Computer and Information Science, Vol. 726, Cham: Springer. https://doi.org/10.1007/978-3-319-61061-0_17

Smith, A. P., \& Smith, H. N. (2017). A Short Questionnaire to Measure Wellbeing at Work (Short-SWELL) and to Examine the Interaction between the Employee and Organisation. In R. Charles, \& J. Wilkinson, (Eds.), Contemporary Ergonomics and Human Factors 2017 (pp. 200-205). Chartered Institute of Ergonomics and Human Factors.

Smith, A., Wadsworth, E., Moss, S., \& Simpson, S. (2004). The Scale and Impact of Drug Use by Workers (Report 193). HSE Research, HSE Books.

Smith, A. P., \& Wadsworth, E. J. K. (2015). The Good Job Score: Associations with Positive and Negative Outcomes. In S. Sharples, S. Shorrock, \& P. Waterson (Eds.), Contemporary Ergonomics and Human Factors 2015 (pp. 267-274). London: Taylor \& Francis.

Swickert, R. J., Rosentreter, C. J., Hittner, J. B., \& Mushrush, J. E. (2002). Extraversion, Social Support Processes, and Stress. Personality and Individual Differences, 32, 877-891.

Tully, A. (2004). Stress, Sources of Stress and Ways of Coping among Psychiatric Nursing Students. Journal of Psychiatric and Mental Health Nursing, 11, 43-47. https://doi.org/10.1111/j.1365-2850.2004.00682.x

Wellens, B. T., \& Smith, A. P. (2006). Combined Workplace Stressors and Their Relationship with Mood, Physiology, and Performance. Work and Stress, 20, 1-14. https://doi.org/10.1080/02678370601022712

Williams, G., Pendlebury, H., \& Smith, A. P. (2017). Stress and Well-Being of Nurses: An Investigation using the Demands-Resources-Individual Effects (DRIVE) Model and Well-Being Process Questionnaire (WPQ). Jacobs Journal of Depression and Anxiety.

Williams, G. M., \& Smith, A. P. (2016). Using Single-Item Measures to Examine the Relationships between Work, Personality, and Well-Being in the Workplace. Psychology: Special Edition on Positive Psychology, 7, 753-767.

https://doi.org/10.4236/psych.2016.76078 http://file.scirp.org/pdf/PSYCH_2016060115074176.pdf

Williams, G., Thomas, K., \& Smith, A. P. (2017). Stress and Well-Being of University Staff: An Investigation using the Demands-Resources-Individual Effects (DRIVE) Model and Well-Being Process Questionnaire (WPQ). Psychology. 


\section{Appendix 1}

\section{Students' Well-being}

The following questions contain a number of single-item measures of aspects of your life as a student and feelings about yourself. Many of these questions will contain examples of what thoughts/behaviours the question is referring to which are important for understanding the focus of the question, but should be regarded as guidance rather than strict criteria. Please try to be as accurate as possible, but avoid thinking too much about your answers, your first instinct is usually the best.

1) I have been feeling in good spirits (for example: I feel optimistic about the future, feel good about myself and confident in my abilities)

Disagree strongly 12345678910 Agree strongly

2) Overall, I feel that I have low self-esteem (For example: At times, I feel that I am no good at all, at times I feel useless, I am inclined to feel that I am a failure)

Disagree strongly 12345678910 Agree strongly

3) On a scale of one to ten, how depressed would you say you are in general? (e.g. feeling "down", no longer looking forward to things or enjoying things that you used to)

Not at all depressed 12345678910 Extremely depressed

4) I have been feeling good about my relationships with others (for example: Getting along well with friends/colleagues, feeling loved by those close to me)

Disagree strongly 12345678910 Agree strongly

5) I feel able to relax when I want to

Disagree strongly 12345678910 Agree strongly

6) I feel energetic and interested when I need to be

Disagree strongly 12345678910 Agree strongly

7) I don't really get on well with people (For example: I tend to get jealous of others, I tend to get touchy, I often get moody)

Disagree strongly 12345678910 Agree strongly

8) Thinking about myself and how I normally feel, in general, I mostly experience positive feelings (For example: I feel alert, inspired, determined, attentive)

Disagree strongly 12345678910 Agree strongly

9) In general, I feel optimistic about the future (For example: I usually expect the best, I expect more good things to happen to me than bad, It's easy for me to relax)

Disagree strongly 12345678910 Agree strongly

10) I am confident in my ability to solve problems that I might face in life (For example: I can usually handle whatever comes my way, If I try hard enough I can overcome difficult problems, I can stick to my aims and accomplish my goals)

Disagree strongly 12345678910 Agree strongly

11) I feel that I am laid-back about things (For example: I do just enough to get by, I tend to not complete what I've started, I find it difficult to get down to 
work)

Disagree strongly 12345678910 Agree strongly

12) I am not interested in new ideas (For example: I tend to avoid philosophical discussions, I don't like to be creative, I don't try to come up with new perspectives on things)

Disagree strongly 12345678910 Agree strongly

13) Overall, I feel that I have positive self-esteem (For example: On the whole I am satisfied with myself, I am able to do things as well as most other people, I feel that I am a person of worth)

Disagree strongly 12345678910 Agree strongly

14) I feel that I have the social support I need (For example: There is someone who will listen to me when I need to talk, there is someone who will give me good advice, there is someone who shows me love and affection)

Disagree strongly 12345678910 Agree strongly

15) Thinking about myself and how I normally feel, in general, I mostly experience negative feelings (For example: I feel upset, hostile, ashamed, nervous)

Disagree strongly 12345678910 Agree strongly

16) I feel that I have a disagreeable nature (For example: I can be rude, harsh, unsympathetic)

Disagree strongly 12345678910 Agree strongly

\section{Coping Style:}

Problem Focused

17) When I find myself in stressful situations, I take a problem-focused approach (e.g. I take one step at a time, I change things about the situation or myself to deal with the issue, I don't let my feelings interfere too much).

Disagree strongly 12345678910 Agree strongly

Seeks Social Support

18) When I find myself in stressful situations, I look for social support (e.g. I talk to someone to get more information, I ask someone for advice, I talk to someone about how I'm feeling).

Disagree strongly 12345678910 Agree strongly

Blame Self

19) When I find myself in stressful situations, I blame myself (e.g. I criticize or lecture myself, I realise I brought the problem on myself).

Disagree strongly 12345678910 Agree strongly

Wishful Thinking

20) When I find myself in stressful situations, I wish for things to improve (e.g. I hope a miracle will happen, I wish I could change things about myself or circumstances, I daydream about a better situation).

Disagree strongly 12345678910 Agree strongly

Avoidance

21) When I find myself in stressful situations, I try to avoid the problem (e.g. I keep things to myself, I go on as if nothing has happened, I try to make myself feel better by eating/drinking/smoking). 
Disagree strongly 12345678910 Agree strongly

22) I prefer to keep to myself (For example: I don't talk much to other people, I feel withdrawn, I prefer not to draw attention to myself)

Disagree strongly 12345678910 Agree strongly

23) I feel that I have an agreeable nature (For example: I feel sympathy toward people in need, I like being kind to people, I'm co-operative)

Disagree strongly 12345678910 Agree strongly

24) In general, I feel pessimistic about the future ( For example: If something can go wrong for me it will, I hardly ever expect things to go my way, I rarely count on good things happening to me)

Disagree strongly 12345678910 Agree strongly

25) I feel that I am a conscientious person (For example: I am always prepared, I make plans and stick to them, I pay attention to details)

Disagree strongly 12345678910 Agree strongly

26) I feel that I can get on well with others (For example: I'm usually relaxed around others, I tend not to get jealous, I accept people as they are)

Disagree strongly 12345678910 Agree strongly

27) I feel that I am open to new ideas (For example: I enjoy philosophical discussion, I like to be imaginative, I like to be creative)

Disagree strongly 12345678910 Agree strongly

28) Overall, I feel that I am satisfied with my life (For example: In most ways my life is close to my ideal, so far I have gotten the important things I want in life)

Disagree strongly 12345678910 Agree strongly

29) On a scale of one to ten, how happy would you say you are in general?

Extremely unhappy 12345678910 Extremely happy

30) On a scale of one to ten, how anxious would you say you are in general? (e.g. feeling tense or "wound up", unable to relax, feelings of worry or panic)

Not at all anxious 12345678910 Extremely anxious

31) In general, how would you rate your physical health

Extremely poor 12345678910 Extremely good

32) Overall, how stressful is your life?

Not at all stressful 12345678910 Very Stressful

Please consider the following elements of student life and indicate overall to what extent they have been a part of your life over the past 6 months. Remember to use the examples as guidance rather than trying to consider each of them specifically:

33) Challenges to your development (e.g. important decisions about your education and future career, dissatisfaction with your written or mathematical ability, struggling to meet your own or others' academic standards).

Not at all part of my life 12345678910 Very much part of my life

34) Time pressures (e.g. too many things to do at once, interruptions of your school work, a lot of responsibilities). 
Not at all part of my life 12345678910 Very much part of my life

35) Academic Dissatisfaction (e.g. disliking your studies, finding courses uninteresting, dissatisfaction with school).

Not at all part of my life 12345678910 Very much part of my life

36) Romantic Problems (e.g. decisions about intimate relationships, conflicts with boyfriends'/girlfriends' family, conflicts with boyfriend/girlfriend).

Not at all part of my life 12345678910 Very much part of my life

37) Societal Annoyances (e.g. getting ripped off or cheated in the purchase of services, social conflicts over smoking, disliking fellow students).

Not at all part of my life 12345678910 Very much part of my life

38) Social Mistreatment (e.g. social rejection, loneliness, being taken advantage of).

Not at all part of my life 12345678910 Very much part of my life

39) Friendship problems (e.g. conflicts with friends, being let down or disappointed by friends, having your trust betrayed by friends).

Not at all part of my life 12345678910 Very much part of my life

Please state how much you agree or disagree with the following statements:

40) There is a person or people in my life who would provide tangible support for me when I need it (for example: money for tuition or books, use of their car, furniture for a new apartment).

Strongly Disagree $\quad 12345678910$ Strongly Agree

41) There is a person or people in my life who would provide me with a sense of belonging (for example: I could find someone to go to a movie with me, I often get invited to do things with other people, I regularly hang out with friends).

Strongly Disagree $\quad 12345678910$ Strongly Agree

42) There is a person or people in my life with whom I would feel perfectly comfortable discussing any problems I might have (for example: difficulties with my social life, getting along with my parents, sexual problems).

Strongly Disagree 12345678910 Strongly Agree

43) In the last two weeks did you find that you have problems of memory (e.g. forgetting where you put things), attention (e.g. failures of concentration), or action (e.g. doing the wrong thing)?

a) at work

Not at all Rarely Occasionally Quite frequently Very frequently

$0 \square 1 \square 2 \quad \square 3 \square 4$

b) outside of work

Not at all Rarely Occasionally Quite frequently Very frequently

$0 \square 1 \square 2 \quad \square 3 \square 4$

44) How frequently in the last two weeks did you find that you were not getting as much work done as you would have liked?

a) at work

Not at all Rarely Occasionally Quite frequently Very frequently

$0 \square 1 \quad \square 2 \square 3 \square 4$ 
b) outside of work

Not at all Rarely Occasionally Quite frequently Very frequently

$0 \square 1 \square 2 \square 3 \square 4$

Submit or recommend next manuscript to SCIRP and we will provide best service for you:

Accepting pre-submission inquiries through Email, Facebook, LinkedIn, Twitter, etc. A wide selection of journals (inclusive of 9 subjects, more than 200 journals)

Providing 24-hour high-quality service

User-friendly online submission system

Fair and swift peer-review system

Efficient typesetting and proofreading procedure

Display of the result of downloads and visits, as well as the number of cited articles Maximum dissemination of your research work

Submit your manuscript at: http://papersubmission.scirp.org/

Or contact psych@scirp.org 